trabalho no desenvolvimento e síntese de materiais fotocatalíticos para química verde.

o prémio de químico experiente foi atribuído a David Milstein do Instituto de Ciência Weizmann em Israel, em reconhecimento pelo seu trabalho no desenvolvimento de reações de síntese importantes, ambientalmente benignas e sustentáveis que geram ou consomem hidrogénio em condições amenas, sem produzir resíduos.

Os prémios foram entregues durante o Congresso IUPAC Virtual de 2021, que decorreu em agosto, num Simpósio especial agendado na área da Química para

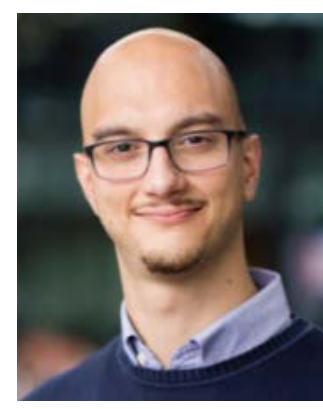

Gabriele Laudadio

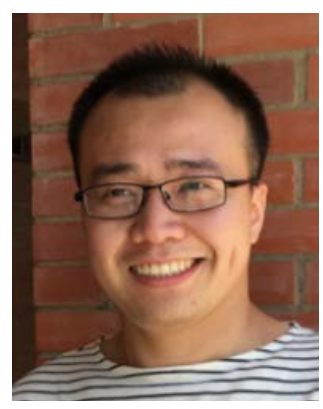

Lichen Liu a Sustentabilidade, em coordenação com o Comité Interdivisional de Química Verde para o Desenvolvimento Sustentável (Interdivisional Committee on Green Chemistry for Sustainable Development, ICGCSD) da IUPAC.

Os vencedores de 2021 do Prémio Internacional IUPAC-Zhejiang NHU irão também preparar um artigo de revisão para publicação numa próxima edição da revista Pure and Applied Chemistry.

$>$

\section{Bruno Machado}

brunofm@fe.up.pt

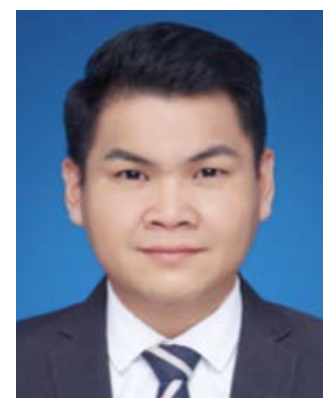

Jingxiang Low

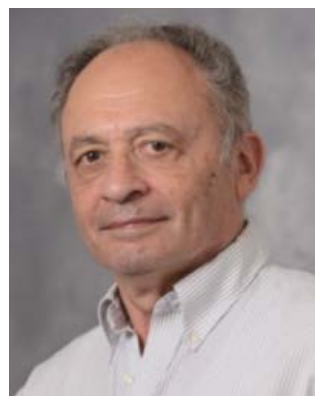

David Milstein

\title{
Prémio Internacional IUPAC-Solvay para Químicos Jovens 2021
}

A União Internacional de Química Pura e Aplicada e a Solvay anunciaram os vencedores do Prémio Internacional IUPAC-Solvay para Químicos Jovens 2021 para as melhores teses de Doutoramento na área da Química. Os cinco vencedores foram:

- Gabriele Laudadio (Itália), Eindhoven University of Technology: New synthetic methods enabled by photochemistry and electrochemistry in flow;

- Justin Andrews (EUA), Texas A\&M University: Corralling Electrons in Metastable Vanadium Oxides: Implications for Neuromorphic Computing, Electrical Energy Storage, and Photocatalysis;

- Kaibo Feng (China), University of Illinois at Urbana-Champaign: Late-Stage $\mathrm{C}\left(s p^{3}\right)-\mathrm{H}$ Hydroxylation, Amination, and Methylation in Nitrogen-Containing Molecules;

- Kelly Brown (Reino Unido), University of Strathclyde: Development of Electrochemiluminescent Sensors as Screening Tools for the Identification of Drug Species within Complex Matrices for Forensic Investigations;
- $\quad$ Austin Michael Evans (EUA), Northwestern University: Two-dimensional polymers and polymerizations.

Cada vencedor recebeu um prémio monetário e foi convidado a apresentar uma comunicação em painel no $48 .^{\circ}$ Congresso Mundial de Química da IUPAC sobre o trabalho premiado. Como o Congresso IUPAC deste ano decorreu virtualmente, os vencedores serão também convidados para o Congresso IUPAC 2023 que será realizado nos Países Baixos. Cada vencedor foi também convidado a submeter um artigo de revisão sobre os aspetos críticos do seu tema de investigação, que será publicado na revista Pure and Applied Chemistry.

Mais informações disponíveis em iupac.org/ winners-of-the-2021-iupac-solvay-international-award-for-young-chemists.

$>$

\section{Bruno Machado}

brunofm@fe.up.pt 